\title{
Nasal Challenge with Ragweed Pollen in Hay Fever Patients
}

\section{Effect of Immunotherapy}

Peter S. Creticos, N. Franklin Adkinson, Jr., Anne Kagey-Sobotka, David Proud, Henry L. Meier, Robert M. Naclerio, Lawrence M. Lichtenstein, and Philip S. Norman

Division of Clinical Immunology, The Johns Hopkins University School of Medicine

at The Good Samaritan Hospital, Baltimore, Maryland 21239

\begin{abstract}
Challenge of the nasal mucosa of allergic subjects with specific allergen induces not only the expected sneezing and rhinorrhea, but also the appearance in nasal secretions of mediators commonly associated with activation of mast cells or basophils: histamine, leukotrienes, prostaglandin $\mathrm{D}_{2}\left(\mathrm{PGD}_{2}\right)$, kinins, and TAME $\left(\left[{ }^{3} \mathbf{H}\right]-N\right.$ - $\alpha$-tosyl-L-arginine methyl ester)-esterase. To determine whether specific immunotherapy alters mediator release in vivo, nasal pollen challenge was used to compare 27 untreated highly sensitive ragweed ( $R W$ )-allergic subjects with 12 similarly sensitive patients receiving long-term immunotherapy (3-5 yr) with $R W$ extract (median dose, $6 \mu \mathrm{g} \mathrm{RW}$ antigen $E)$. The two groups were equally sensitive based on skin tests and basophil histamine release. The immunized group had a diminished response as demonstrated by $(a)$ the treated group required higher pollen doses to excite sneezing or mediator release; (b) significantly fewer subjects in the treated group released mediators at any dose (TAME-esterase $[P=0.005]$, PGD $_{2}[P$ $=0.04])$, and $(c)$ the treated group released 3-5-fold less mediator (TAME-esterase $[P=0.01]$, and histamine $[P=0.02]$ ).
\end{abstract}

\section{Introduction}

Up to now, only indirect evidence has suggested that the pathogenesis of allergic rhinitis involves the interaction between inhaled allergen and mast cell/basophil surface-fixed IgE antibody with the generation of a variety of active metabolites and mediators (1-3). These mediators include the lipoxygenase products (leukotrienes C4/D4/E4) and cyclooxygenase products (prostaglandin $\left.\mathrm{D}_{2}\left[\mathrm{PGD}_{2}\right]\right)^{1}$ of arachidonic acid metabolism, plateletactivating factor, histamine, various chemotactic factors, and enzymes TAME $\left(\left[{ }^{3} \mathrm{H}\right]-\mathrm{N}\right.$-a-tosyl-L-arginine methyl ester)-esterase, tryptases, kininogenases, and lysosomal hydrolases $(4,5)$.

Using the nose as an experimental model, Blackley dem-

This paper is publication No. 624 of the O'Neill Research Laboratories at the Good Samaritan Hospital. 1985.

Received for publication 13 July 1984 and in revised form 9 July

1. Abbreviations used in this paper: $\mathrm{AgE}$, antigen $\mathrm{E}$; MWT, Mann-Whitney U Test; PG, prostaglandin; $\mathrm{PGD}_{2}, \mathrm{PGE}_{1}, \mathrm{PGE}_{2}, \mathrm{PGF}_{1 \alpha}$, and $\mathrm{PGF}_{2 \alpha}$, prostaglandins $\mathrm{D}_{2}, \mathrm{E}_{1}, \mathrm{E}_{2}, \mathrm{~F}_{1 \alpha}$, and $\mathrm{F}_{2 \alpha} ;$ PIPES, piperazine- $N-N^{1}$-bis- $-(2$ ethane-sulfonic acid; PA, PIPES-albumin buffer, PACM, PIPES-albumin buffer with $\mathrm{Ca}$ and $\mathrm{Mg}$; PNU, protein nitrogen units; $r_{\mathbf{s}}$, Spearman's rank correlation coefficient; STS, skin test sensitivity; TAME, TAME $\left(\left[{ }^{3} \mathrm{H}\right]-N\right.$ - $\alpha$-tosyl-L-arginine methyl ester)-esterase.

J. Clin. Invest.

(c) The American Society for Clinical Investigation, Inc. 0021-9738/85/12/2247/07 \$1.00

Volume 76, December 1985, 2247-2253 onstrated in 1873 that grass pollen placed in the nose of sensitive individuals induced signs and symptoms of grass pollenosis (6). Some $100 \mathrm{yr}$ later, Connell (7) and McLean (8) studied the effect of intranasal pollen challenge on nasal airway resistance, and demonstrated that nasal airway resistance increased in response to pollen challenge. Recently, Naclerio et al. (9) described a modified technique of nasal challenge with pollen that allowed collection of nasal secretions by serial lavage and analysis for the presence of mediators. Using this technique, we have obtained direct evidence for the release of many inflammatory mediators into nasal secretions after nasal challenge of pollensensitive patients. Histamine, $\mathrm{PGD}_{2}$, a TAME-esterase (9) leukotriene activity (10), and kinins (11) appear in quantities dependent on the challenge dose of pollen, and mediator production is correlated with symptoms as represented by sneezing.

A continuing problem in the evaluation of immunotherapy with a specific extract is that most allergic people have multiple allergies, whereas the treatment has the expected immunologic specificity (12). Despite careful selection of patients, purely clinical methods of evaluation such as symptom diaries often fall short in providing definitive answers. According to symptoms diary studies, treatment with a particular extract furnishes at best less than complete relief of symptoms attributed to that allergen (13). Such a result may be attributed either to the inherent limitation of immunotherapy or to failure to treat with all the allergens relevant to symptoms. As a laboratory challenge performed when the patient is asymptomatic reproduces the disease due to single allergen exposure for a distinct time interval, it should be a better way to assess the extent to which patients are protected by specific immunotherapy against specific exposure.

In this present study, we have applied the technique of nasal pollen challenge to examine a group of patients on long-term, high-dose immunotherapy with ragweed pollen extract. The clinical and mediator response to pollen challenge was compared with a group of highly sensitive ragweed-allergic patients not on immunotherapy. The results indicate that high-dose immunotherapy with an appropriate antigen mitigates the allergic reaction by altering the immunologically induced secretion of mediators in response to pollen exposure. Protection, however, is less than complete, as challenge doses higher than most natural exposure still elicit some mediator release and symptoms.

\section{Methods}

(A) Patients. Written informed consent was obtained from a newly recruited group of 27 patients, ages 18-55 yr, who displayed seasonal ragweed pollenosis of at least $2 \mathrm{yr}$ duration, and who had not been on immunotherapy within the previous $15 \mathrm{yr}$. A similar group of 12 patients on long-term (3-5 yr), high-dose (1.2-18.6- $\mu \mathrm{g} \mathrm{AgE} \mathrm{equivalent} \mathrm{injection)}$ ragweed immunotherapy were recruited from Van Metre's standard immunotherapy study (13) as a comparison population.

(B) Reagents. Ragweed pollen was purchased from Greer Labora- 
tories (Lenoir, $\mathrm{NC}$ ) for nasal challenge and contained $6.7 \pm 0.2 \mu \mathrm{g}$ of ragweed $\mathrm{AgE} / \mathrm{mg}$ pollen. Ragweed extract employed for skin testing the former group and newly recruited patients contained $336 \pm 12 \mu \mathrm{g}$ antigen $\mathrm{E}(\mathrm{AgE}) / \mathrm{ml}$ in a $1: 20 \mathrm{wt} / \mathrm{vol}(59,600$ protein nitrogen units [PNU]) glycerinated extract.

Buffers for leukocyte histamine release. (a) PA, which contains 25 mM PIPES [piperazine- $N$ - $N^{1}$-bis-(2 ethane-sulfonic acid; Sigma Chemical Co., St. Louis, MO)], $110 \mathrm{mM} \mathrm{NaCl}, 5 \mathrm{mM} \mathrm{KCl}$, and $0.01 \%$ human serum albumin, was used to wash the leukocytes. (b) PACM, used for release studies, contained, in addition to the above, $0.6 \mathrm{mM} \mathrm{CaCl}_{2} \cdot 6 \mathrm{H}_{2} \mathrm{O}$ and $1.0 \mathrm{mM} \mathrm{MgCl}_{2}$. The buffers were adjusted to $\mathrm{pH} 7.3$ before use.

(C) Skin tests. Intradermal end-point titrations were performed according to the method of Norman (14) on both patient groups.

(D) Histamine release. Venous blood was drawn from the subjects after obtaining informed consent. It was placed in dextran-EDTA for $90 \mathrm{~min}$, washed twice in PA, and the leukocytes suspended in PACM before challenge (15). Individual assay tubes usually contained the leukocytes from $0.5 \mathrm{ml}$ of whole, peripheral blood. The release reaction was initiated by the addition of various concentrations $\left(0.1-10^{-5} \mu \mathrm{g} / \mathrm{ml}\right)$ of short ragweed pollen extract (kindly supplied by Hollister-Stier Laboratories, Spokane, WA) and allowed to proceed for $45 \mathrm{~min}$ at $37^{\circ} \mathrm{C}$. After the release reaction, the leukocytes were removed by centrifugation $(1,000 \mathrm{~g}$ for $1 \mathrm{~min})$, and the supernatants assayed for histamine content. The difference between replicate histamine measurements was $<5 \%$. Aliquots of cells in the same total volume were lysed with $2 \%$ perchloric acid $\left(\mathrm{HClO}_{4}\right)$ to evaluate total histamine. Each study included control tubes containing cells to which no stimulus was added. Spontaneous histamine release (2-5\% of the total histamine) was subtracted from all values and the percentage histamine release calculated. Dose-response curves were constructed by plotting the percentage histamine release vs. the concentration of $\mathrm{AgE}$ equivalents, and the amount of antigen required for $50 \%$ histamine obtained for each subject. Histamine was measured using an automated fluorometric technique (16).

The group of immunized patients had had skin tests, in vitro studies, and immunotherapy performed with a short ragweed extract that contained $187 \mu \mathrm{g} \mathrm{AgE} / \mathrm{ml}$ in a 1:20 wt/vol (40,000 PNU) glycerinated extract provided by Hollister-Stier Laboratories. Dilutions were made in $0.03 \%$ human serum albumin for skin testing and injections.

(E) Nasal challenge technique. These techniques have been described in detail $(9,17)$. All challenges were performed outside the ragweed season (either before or $\geq 6 \mathrm{wk}$ past) at a time when patients were asymptomatic. Briefly, varying amounts of ragweed pollen were combined with lactose to obtain a total weight of $25 \mathrm{mg}$ in a gelatin capsule. The individual capsules were then insufflated in the particular nostril via a Spinhaler (Fisons Corp., Bedford, MA) apparatus connected to a Rosenthal-French dosimeter. With activation (four activations for $2 \mathrm{~s}$ with a driving pressure of 10 pounds per square inch), $\sim 22 \mathrm{mg}$ of pollen and lactose $( \pm 15 \%)$ were expelled into the nose. The capsule was examined to insure that it had been emptied.

Nasal secretions were collected by nasal lavage. The subject was instructed to tilt his head at a $30^{\circ}$ angle from the horizontal in a sitting position, and $5 \mathrm{ml}$ of normal saline (Cutter Laboratories, Emeryville, CA) was instilled into each nostril while the patient held his breath and did not swallow. After $10 \mathrm{~s}$, the patient expelled the mixture of mucus and saline into a collection vessel. These samples were maintained on ice until the challenge was complete. Subsequently, all samples were centrifuged at $15,000 \mathrm{~g}$ and $4^{\circ} \mathrm{C}$ for $15 \mathrm{~min}$ and the sol phase separated from the gel (mucus) phase. Samples were stored at $-80^{\circ} \mathrm{C}$ until assayed.

Table I illustrates our protocol, which involves prechallenge saline washes to reduce levels of cell-free mediators typically present in early nasal secretions. Then Afrin (oxymetazoline hydrochloride, Schering Corp.) is sprayed into the nose (two sprays per nostril) to maintain nasal patency during the allergic reaction so that nasal secretions can be collected. Previous study has shown that this drug dose does not effect mediator release. Subsequently, two challenges with a lactose diluent are employed to establish a base line. Thereafter, serial challenges with 10/ $100 / 1,000 / 5,000$ grains of ragweed pollen at 10-min intervals were undertaken and a saline wash $(8.0 \pm 1.5 \mathrm{ml})$ was collected 10 min after each pollen challenge dose to allow measurement of the various inflammatory mediators produced in nasal secretions.

(1) Nasal challenge with lactose (placebo). A previous paper from our laboratory addressed the use of lactose as a placebo challenge. In 105 experiments, sneezing occurred in only $7.6 \%$ of the lactose challenges, and the method of delivery affected the concentration of mediators in $<2 \%$ of the experiments performed (2/105) (9). In our study, each patient had two placebo (lactose) challenges as part of the protocol for each serial pollen challenge. In 52 lactose challenges ( 26 patients), only one patient sneezed $(1.9 \%)$, and none released significant amounts of any mediator.

(2) Nasal challenge of nonallergic controls. We challenged four nonallergic subjects with 5,000 grains of pollen who showed no clinical response or evidence of mediator release in nasal secretions as measured by our assay techniques (10).

(3) Reproducibility of pollen challenge. 26 untreated patients all underwent identical repeat pollen challenge between 2 and 5 mo after their first challenge. Fig. 1 shows the reproducibility of the nasal challenge technique; the second challenges demonstrated practically overlapping curves for the number of patients releasing TAME-esterase or histamine $(P>0.1$; Wilcoxon Signed Rank Matched Pairs). The clinical parameter of sneezing was likewise not significantly different $(P>0.05)$. Fig. 2 shows that the patients released similar amounts of mediator (histamine/ TAME-esterase) on repeat pollen challenge $(P=>0.05$ analysis of variance). In a previous paper, we demonstrated that three serial challenges with the same amount of pollen extract on the same day showed essentially equal concentrations of TAME-esterase and numbers of sneezes after each of the challenges (18).

(F) Mediator assays. Frozen aliquots of the sol phase of nasal secretions were thawed and assayed for mediator content as follows:

(1) Histamine. For histamine determinations, $0.8 \mathrm{ml}$ of sample was mixed with $0.2 \mathrm{ml}$ of $8 \% \mathrm{HClO}_{4}$ and centrifuged for $10 \mathrm{~min}$ at $1,000 \mathrm{~g}$. Histamine in the supernatants was assayed by an automated spectrofluorometric assay (16) with a sensitivity of $1 \mathrm{ng} / \mathrm{ml}$ and an accuracy of $\pm 5 \%$.

(2) TAME-esterase. Enzyme(s) having arginine esterase activity were assayed essentially by the method of Imanari et al. (19), which is based on the liberation of tritiated methanol from the synthetic substrate TAME. A 40- $\mu$ l aliquot of nasal sample and $10 \mu \mathrm{l}$ of $0.2 \mathrm{M}$ Tris buffer, $\mathrm{pH} 8.0$, are added to a $1.5 \mathrm{ml}$ Eppendorf microtube. A $10-\mu \mathrm{l}$ vol $\left(1.5 \times 10^{5} \mathrm{cpm}\right)$ of ${ }^{3} \mathrm{H}$-TAME (Amersham Corp., Arlington Heights, IL) was then added with mixing and the tube was placed in a counting vial containing 10 $\mathrm{ml}$ of econofluor (New England Nuclear, Boston, MA) and $50 \mu \mathrm{l}$ of stop solution (1 vol glacial acetic acid, 9 vol $0.02 \mathrm{M}$ TAME). The counting

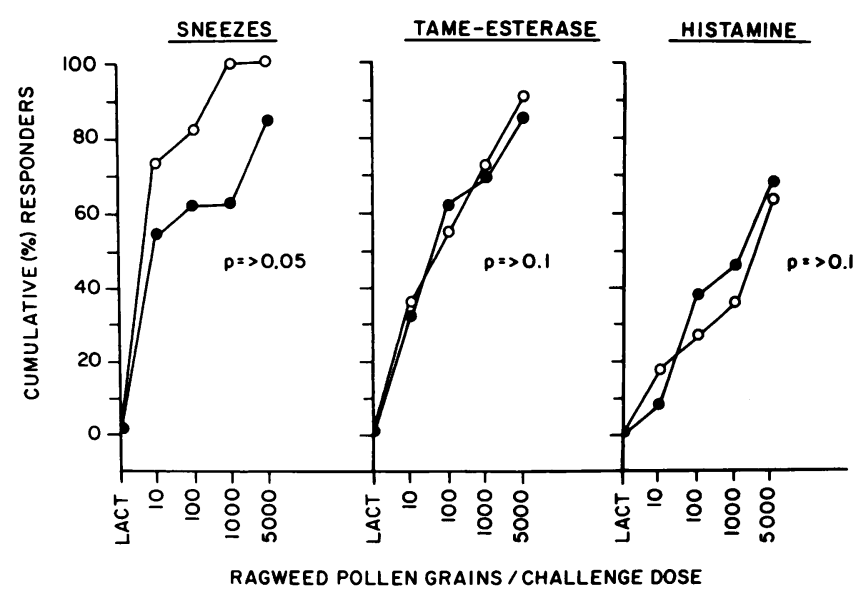

Figure 1. Cumulative percentage (\%) of untreated patients $(n=26)$ sneezing or demonstrating mediator release to serial pollen challenge (10-5,000 grains) on two separate occasions. $\bullet$, Initial challenge; $\circ$, repeat challenge. 


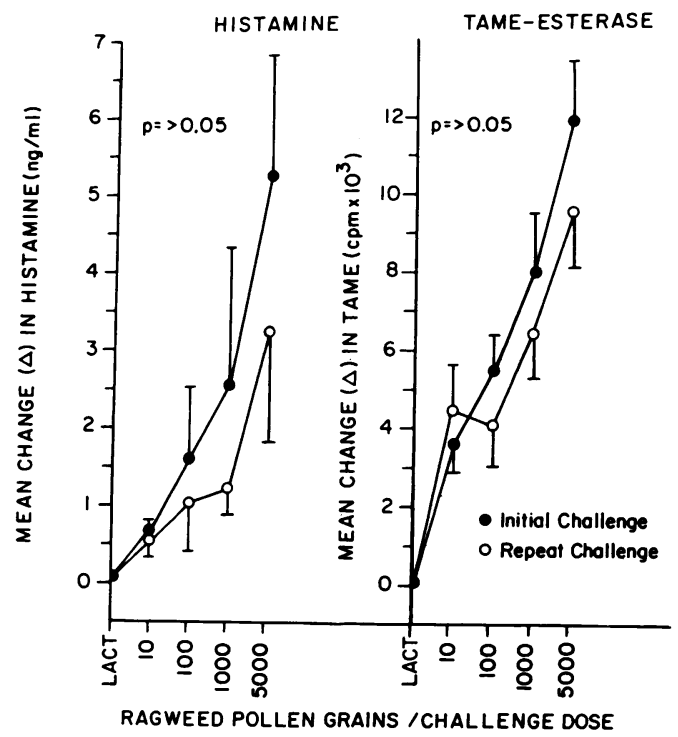

Figure 2. Absolute amount of mediator released over base-line levels for untreated patients challenged on two separate occasions. (For histamine, $n=21 / 21 / 21 / 17$ at each respective dose. For TAME-esterase, $n=20 / 20 / 19 / 15$ at each respective dose.)

vial was then tightly capped, and after $1 \mathrm{~h}$ the reaction was terminated, and tritiated methanol was partitioned into the econofluor by shaking. The vial was then counted for $4 \mathrm{~min}$ in a liquid scintillation spectrometer, and the levels of TAME-esterase computed by reference to standards. The sensitivity of the assay is $1,000 \mathrm{cpm}$ above background.

(3) $P G D_{2} . \mathrm{PGD}_{2}$ was measured by a competitive radioimmunoassay (RIA) as previously described (20). The anti-PGD ${ }_{2}$ was prepared in rabbits using $\mathrm{PGD}_{2}$-bovine thyroglobulin conjugates (21). This antibody has a cross-reactivity of $<1 \%$ for $\mathrm{PGE}_{1}, \mathrm{PGE}_{2}$, thromboxane $\mathrm{B}_{2}, 6$-keto-PGF $\mathrm{P}_{1 \alpha}$, and $\mathrm{PGF}_{2 \alpha}$. Tritiated $\mathrm{PGD}_{2}$ (New England Nuclear) was added to the nasal washes as a standard, and the nasal washes containing $\mathrm{PGD}_{2}$ diluted in parallel with authentic $\mathrm{PGD}_{2}$. The sensitivity of the assay is $20 \mathrm{pg} / \mathrm{ml}$.

(G) Definitions. A positive clinical response to pollen challenge was defined as sneezing in response to antigen challenge. Mediator release was defined as positive if a threefold or 3-U increase above the base line (second secretion collected after challenge) occurred in the nasal wash after antigen challenge.

Since the assays for a particular mediator demonstrate different sensitivities, criteria were established to define a significant rise (positive response) with each mediator. Obviously, when base-line levels were measurable, then a threefold rise was required to define a positive response. Otherwise, for histamine, with a sensitivity of $1 \mathrm{ng} / \mathrm{ml}$, if the base-line level was below the sensitivity of the assay, an increase to $3 \mathrm{ng} /$ $\mathrm{ml}$ was required to be considered a positive response. Likewise for $\mathrm{PGD}_{2}$, with a sensitivity of $20 \mathrm{pg} / \mathrm{ml}$, a rise to at least $60 \mathrm{pg} / \mathrm{ml}$ was required to be significant. With TAME-esterase (sensitivity of $1,000 \mathrm{cpm}$ ), a rise to $3,000 \mathrm{cpm}$ or greater was required for a positive response. The dose threshold for mediator release was taken on the first challenge dose that resulted in positive mediator release that was sustained or increased at higher doses.

(H) Statistics. The Spearman Rank Correlation Coefficient was used to compare skin test sensitivity (STS), basophil sensitivity, or mediator release within the respective group. Nonparametric statistics were employed for analysis of data between the two groups. (The Mann-Whitney U Test [MWT] was used for analysis of basophil histamine release, cumulative response, and amount of mediator release between two groups; whereas, the Wilcoxon Matched Pairs Signed Rank Test was used to analyze data within a group). Analysis of variance for repeated measures was used to analyze the reproducibility data for the amount of meditor released. The Fisher Exact Test was employed to analyze discrete points (22).

\section{Results}

(A) STS of nontreated and treated groups of patients. STS in the nontreated group of patients $(n=27)$ ranged from $1.3 \times$ $10^{-6}$ to $6.7 \times 10^{-2} \mu \mathrm{g} \mathrm{AgE} / \mathrm{ml}$, medial $3.4 \times 10^{-5} \mu \mathrm{g} \mathrm{AgE} / \mathrm{ml}$ (wt/vol: range 1:5 billion to 1:100,000, median 1:200 million; PNU: range $2.4 \times 10^{-4}$ to $1.2 \times 10^{1}$, median $2.4 \times 10^{-3}$ ). STS in the treated group of patients $(n=12)$ similarly ranged from $3.8 \times 10^{-6}$ to $1.2 \times 10^{-2}$, median $1.9 \times 10^{-5} \mu \mathrm{g} \mathrm{AgE} / \mathrm{ml}(\mathrm{wt} /$ vol: range 1:5 billion to 1:312,500, median 1:200 million; PNU: range $8 \times 10^{-4}$ to $2.6 \times 10^{0}$, median $4 \times 10^{-3}$ ).

(B) Comparison of the nontreated and treated groups by basophil histamine release. We have previously demonstrated that groups of patients matched based on the amount of antigen required for $50 \%$ histamine release from leukocytes (basophil histamine release) are matched in terms of STS and clinical symptoms, as measured by symptom scores from daily diaries during natural pollen exposure $(12,23)$. Fig. 3 shows that the nontreated and treated groups of patients have comparable pretreatment basophil and sensitivity $(P=0.22$, MWT $)$, and suggests that although obtained in a retrospective manner, the treated group was comparable to the untreated group.

(C) Comparison of nasal mediator release and STS and basophil sensitivity in the nontreated group. In the 26 nontreated patients, STS did not correlate with either the maximum amount of mediator released or with the log threshold dose for mediator release. This relationship for the threshold for TAME-esterase activity was Spearman's rank correlation coefficient $\left(r_{\mathrm{s}}\right)=0.26$, $P=>0.1$. Similar findings were observed for $\operatorname{PGD}_{2}\left(r_{\mathrm{s}}=0.03\right.$, $P=>0.1)$ and histamine $\left(r_{s}=0.1, P=>0.2\right)$. Thus, the patients highly sensitive by skin testing were not more likely to have earlier or greater mediator release than somewhat less skin-sensitive patients.

In a similar fashion, basophil sensitivity as determined by the dose of ragweed AGE required for $50 \%$ histamine release from the patients' leukocytes did not correlate with the threshold for release of a mediator. (TAME-esterase $\left[r_{\mathrm{s}}=0.12, P=>0.1\right]$,

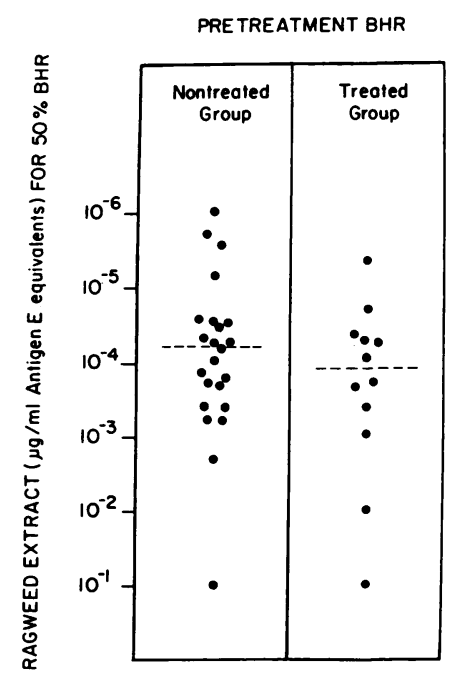

Figure 3. Basophil histamine release (BHR) $(\bullet)$ representing discrete points for each individual patient for the amount of antigen required for $50 \%$ histamine release $(P=0.22 \mathrm{MWT})$. 


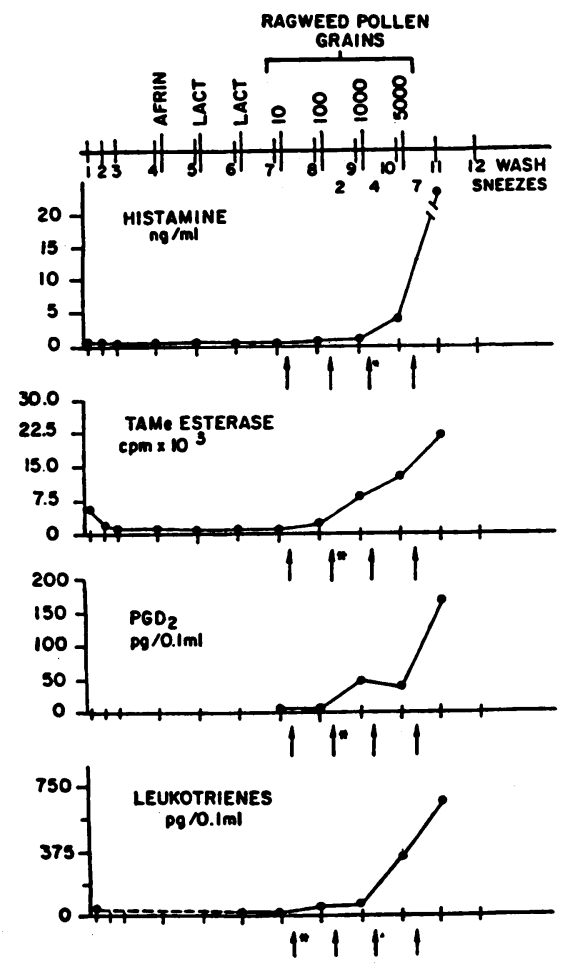

Figure 4. Typical subject response to pollen challenge. Vertical axes display respective units. 10/100/1,000/5,000 represent particular ragweed pollen challenge dose. Closed circles represent nasal washes obtained at 10 -min intervals after the initial three washes.

$\mathrm{PGD}_{2}$ and histamine $\left.\left[r_{\mathrm{s}}=0.15, P=>0.1\right]\right)$. However, as we have reported here, STS in the nontreated group was significantly correlated with basophil sensitivity $\left(r_{\mathrm{s}}=0.53, P=<0.01\right)$.

(D) Typical subject response to nasal pollen challenge. Fig. 4 demonstrates a typical dose response to nasal ragweed pollen challenge. The onset of sneezing at the 100 -grain pollen challenge correlated with the initial appearance of mediators and both clinical response and mediator release increase in a dose-related fashion. TAME-esterase and $\mathrm{PGD}_{2}$ release were first detected in response to the 100-grain pollen challenge. However, a rise in histamine was not detected until the 1000 -grain pollen dose.

$(E)$ Response rates for sneezing and mediator detection in the nontreated patient group. In previous studies, we have demonstrated both concordance between sneezing and mediator release $(P=<0.001$; Fisher Exact Test $)$ and concordance among the thresholds for release of these mediators $(P=<0.001)(9)$. In this present study, among the untreated patient groups, $89 \%$ $(23 / 26)$ of subjects sneezed and $22 / 23(96 \%)$ of subjects who sneezed released one or more mediators. The data in Fig. 5 (closed circles represent untreated patients) indicate that 24/26 (92\%) of untreated subjects released TAME-esterase, 14/26 (54\%) released $\mathrm{PGD}_{2}$, and $16 / 26(62 \%)$ released histamine. The close association between sneezing and TAME-esterase release is again demonstrated here. In addition, note that the threshold dose for detection of TAME-esterase was lower than the dose for either histamine or $\mathrm{PGD}_{2}$ release $(P=<0.01$; Wilcoxon Matched Pairs Signed Rank Test). As can be seen, (14/26) $54 \%$ of the subjects released TAME at just 10 pollen grains, whereas in only $7 / 26$ $(27 \%)$ and $1 / 26(4 \%)$, respectively, could we demonstrate $\mathrm{PGD}_{2}$ and histamine at this low pollen dose. Thus, TAME-esterase is

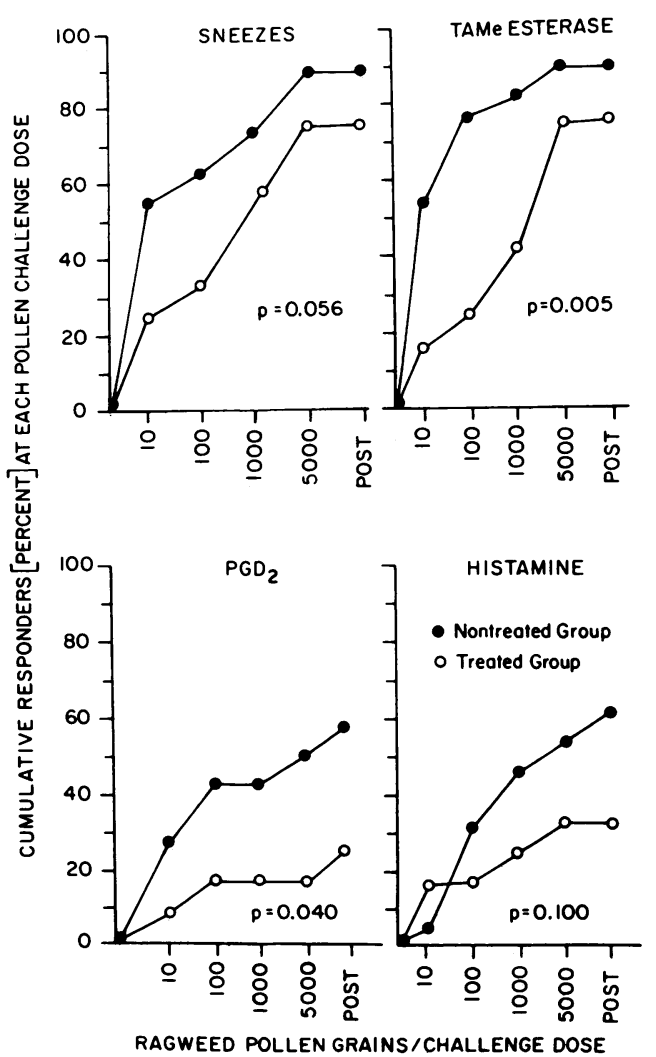

Figure 5. Comparison of the nontreated $(n=26)(\bullet)$ and treated $(n$ $=12$ ) (0) groups of patients based on cumulative percentage $(\%)$ of patients sneezing or demonstrating mediator release at each respective pollen challenge dose. Statistical comparison made on the threshold dose of pollen required to provoke a significant response (employing the MWT).

the most sensitive indicator of mediator release in the allergic response in the nose, and is most closely associated with the clinical symptom of sneezing.

$(F)$ Comparison of treated and nontreated ragweed-sensitive patients by clinical parameters and mediator release. Although a comparable proportion of both groups sneezed during the course of the nasal pollen challenge procedure (nontreated [89\%] vs. treated [75\%]), patients on immunotherapy required larger threshold pollen doses to provoke sneezing than untreated patients of comparable pretreatment sensitivity by skin tests and basophil histamine release $(P=0.056, \mathrm{MWT})$ (Fig. 5). Similarly, treated patients required significantly higher threshold doses of pollen to elicit release of TAME-esterase $(P=0.005$, MWT) and $\mathrm{PGD}_{2}(P=0.04, \mathrm{MWT})$, but not histamine $(P=0.1, \mathrm{MWT})$, probably in the latter case because of the low number of responders detected.

$(G)$ Comparison of the amount of mediator released by treated and nontreated patients. The data in Fig. 6 show that patients on immunotherapy released less TAME-esterase and histamine as compared with the nontreated group at all doses. Because there were too few responders at the lower doses among the treated patients, an MWT was performed on the amount of mediator released at the highest dose $(5,000$ pollen grains) $(P$ $=0.01$ for TAME-esterase and $P=0.02$ for histamine). Although less $\mathrm{PGD}_{2}$ was released on nasal pollen challenge in the treated group, significance was not demonstrated because of the low 

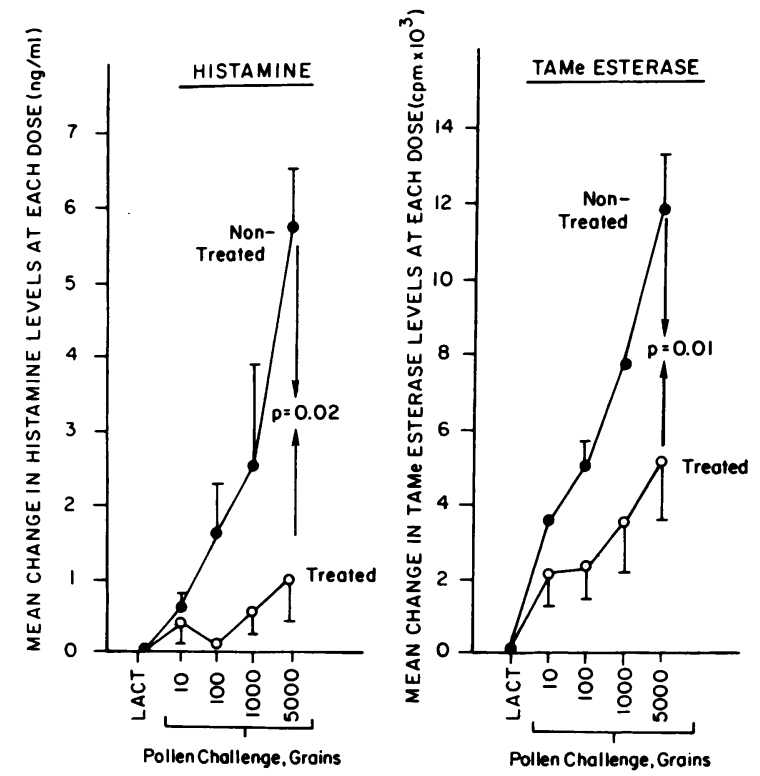

numbers of responders even at the 5,000-grain pollen dose ( $P$ $=0.2, \mathrm{MWT}$ ).

\section{Discussion}

Efforts in our laboratory have long been directed toward understanding the pathophysiology of the allergic response by studying the IgE-mediated release of inflammatory mediators in vitro from purified human basophils and lung mast cells $(3,24)$. The nasal challenge model (Table I) allows us to study the allergic reaction in vivo both by observation of clinical symptoms and measurement of mediator release (9). Previous studies (9-11) elaborated on the concordance between mediator release and sneezing $(P=<0.001)$ and the close association between the various mediators. In this paper we demonstrate that TAMEesterase activity is the most sensitive indicator of the allergic response currently available, and significantly correlates with the clinical symptom of sneezing. (Fig. 5 shows that $92 \%$ of the untreated subjects demonstrated TAME-esterase activity during pollen challenge, and this activity closely paralleled the sneezing response.) Histamine and $\mathrm{PGD}_{2}$ release was detected in the majority of patients, but at somewhat higher pollen doses. The 1$\mathrm{ng} / \mathrm{ml}$ sensitivity of the histamine assay limits our ability to observe rises; a more sensitive assay might more readily detect lower levels of mediator release. It is likely that differences in the threshold of challenge required for significant release of different mediators reflects only the sensitivity of the several assays.

The lack of correlation between the threshold of skin response and $50 \%$ end point of basophil histamine release on one hand, and the threshold of responses to challenge on the other hand, may be attributed to performing challenges with whole pollen and skin tests and histamine release with an extract. Although both materials should contain the same basic ingredients, the mix to which the patient is exposed may be quite different in the two cases, as pollen resides on the mucosa for only a few minutes for allergens to be leached out, whereas extracts involve a 24-h exposure of pollen to water. Nevertheless, skin tests and basophil histamine release have served repeatedly to develop

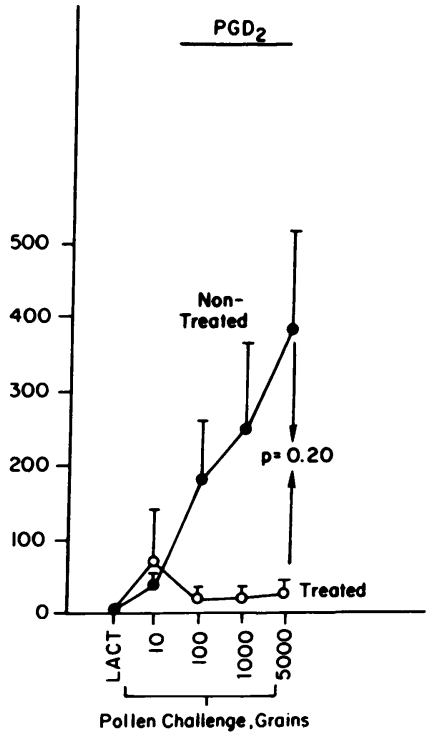

Figure 6. Absolute amount of mediator released over base-line levels for the nontreated $(n=26)(\bullet)$ and treated $(n=12)(0)$ groups of patients. Statistical comparison made on the maximum increase in mediator produced over base-line values (employing the MWT).

\section{Table I. Basal Challenge Protocol}

Base-line protocol

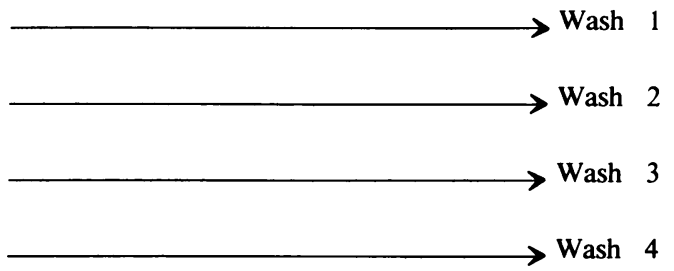

Nasal decongestant

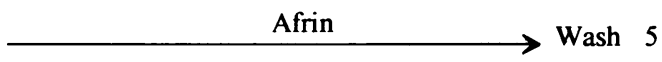

Diluent insufflation

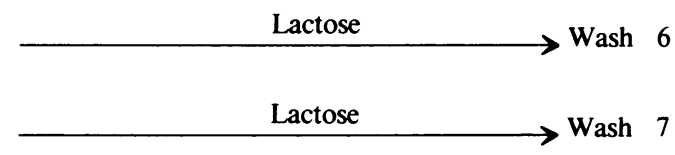

Pollen challenge

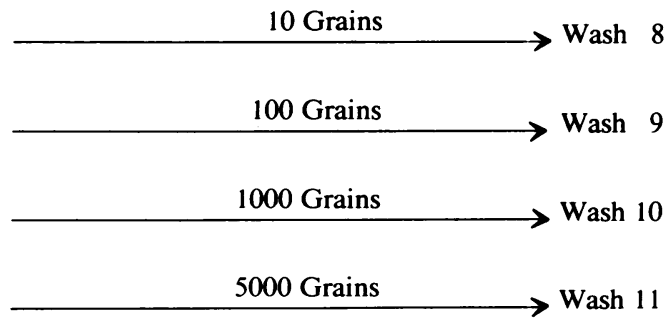

Postchallenge 
matched groups of patients for therapeutic comparisons $(12,23)$.

In this present study, we have applied the technique of nasal pollen challenge to examine a group of patients on long-term, high-dose immunotherapy. Nasal challenge, out of season, simulates natural exposure, and provides a method for comparing responses with a specific pollen challenge without interference from responses to other allergens. We have compared a group of successfully immunized patients with a similar group of highly sensitive ragweed-allergic patients not on immunotherapy.

Significantly, fewer immunized patients (Fig. 5) released inflammatory mediators indicative of the allergic response (TAMEesterase activity $[P=0.005] ; \mathrm{PGD}_{2}$ release $\left.[P=0.04]\right)$. The clinical parameter of sneezing was also diminished in the treated group $(P=0.056)$. The thresholds for both mediator release and sneezing were shifted to the right, thereby requiring higher pollen challenge doses than typically encountered in natural exposure to elicit a comparable response. Our calculations suggest that during a pollen season, an average of 60 ragweed pollen grains are inhaled per hour, with a peak exposure of $\sim 315$ ragweed pollen grains inhaled per hour. Thus, the 1,000- and 5,000-grain challenges are probably in excess of natural exposure, but do demonstrate that reactivity has not been completely ablated. Even so, the actual absolute concentrations of mediators released upon large challenges were 3-5-fold lower in the immunized group than in the nontreated group (Fig. 6).

Our data indicate suppression of the immediate mast cell response, but Dolovich and others $(25,26)$ have pointed out that the late-phase IgE-mediated component of an allergic reaction may also be an essential feature of allergic disease. For instance, appearance of neutrophil chemotactic activity, histamine $(27,28)$, and a human macrophage-derived product (29) several hours after challenge have been described. Furthermore, basophillike cells are found in the airway mucosa (30) and accumulate at the site of a late-phase IgE-mediated inflammatory reaction (31-33). We have recently shown that late-phase (3$11 \mathrm{~h})$ IgE-mediated reactions in the nose are associated with reappearance of most of the early mediators (with the notable exception of $\mathrm{PGD}_{2}$ ) along with a recrudescence of symptoms (31).

The data in this paper do not examine how immunotherapy might change mediator release. Several earlier studies show that the clinical response to immunotherapy is specific for the species of allergen employed (12), thus providing evidence for immunologic specificity. Nevertheless, description of the immunologic mechanism responsible for therapeutic efficacy has been difficult, and changes in immunologic parameters such as serum IgE and IgG antibodies fail to correlate well with clinical improvement measured by symptom diaries during natural exposure (12). A quantitative challenge with the actual allergen out of season, such as described here, accompanied by observation of both early- and late-phase reactions should allow a more accurate look at mechanisms. A prospective study of the same patients before and after immunotherapy, and correlating changes in response to nasal challenge with changes in antibodies and cellular reactions in blood and secretions, should help to unravel the problem.

\section{Acknowledgments}

We wish to thank Margaret Newton for her technical assistance, and Rita Braun and Lynda Miller for their preparation of the manuscript.
This paper was supported by grants AI-04866, AI-20136, and HL32272 from the National Institutes of Health.

\section{References}

1. Norman, P. S. 1975. The clinical significance of IgE. Hosp. Pract. 10:41-49.

2. Ishizaka, T., F. Hirata, K. Ishizaka, and J. Axelrod. 1980. Stimulation of phospholipid methylation, $\mathrm{Ca}^{2+}$ influx, and histamine release by bridging of IgE receptors on rat mast cells. Proc. Natl. Acad. Sci. USA. 77:1903-1906.

3. Lichtenstein, L. M., R. P. Schleimer, D. W. MacGlashan, Jr., S. P. Peters, E. S. Schulman, D. Proud, P. S. Creticos, R. M. Naclerio, and A. Kagey-Sobotka. 1984. In vitro and in vivo studies of mediator release from human mast cells. In Asthma III: Physiology, Immunopharmacology and Treatment. A. B. Kay, L. M. Lichtenstein, and K. F. Austen, editors. Academic Press, Inc., London. 1-18.

4. Lewis, R. A., and K. F. Austen. 1981. Mediation of local homeostasis and inflammation by leukotrienes and other mast cell dependent compounds. Nature (Lond.). 293:103-108.

5. Wasserman, S. I. 1983. Mediators of immediate hypersensitivity. J. Allergy Clin. Immunol. 72:101-115.

6. Blackley, C. H. 1873. Experimental Researches on the Cause and Nature of Catarrhus Reactions (Hay Fever or Hay Asthma). Bailliere Tindal and Cox, Ltd., London.

7. Connell, J. 1968. Quantitative intranasal pollen challenge. J. Allergy. 41:123-139.

8. McLean, J. A., A. A. Ciarkowski, W. R. Solomon, and K. P. Matthews. 1976. An improved technique for nasal inhalation challenge tests. J. Allergy Clin. Immunol. 57:153-163.

9. Naclerio, R. M., H. L. Meier, A. Kagey-Sobotka, N. F. Adkinson, Jr., D. A. Meyers, P. S. Norman, and L. M. Lichtenstein. 1983. Mediator release after nasal airway challenge with allergen. Am. Rev. Respir. Dis. 128:597-602.

10. Creticos, P. S., S. P. Peters, N. F. Adkinson, Jr., R. M. Naclerio, E. C. Hayes, P. S. Norman, and L. M. Lichtenstein. 1984. Demonstration of peptide-leukotriene release following nasal antigen challenge in vivo. N. Engl. J. Med. 310:1626-1630.

11. Proud, D., A. Togias, R. M. Naclerio, S. A. Crush, P. S. Norman, and L. M. Lichtenstein. 1983. Kinins are generated in vivo following nasal airway challenge of allergic individuals with allergen. J. Clin. Invest. 72:1678-1685.

12. Norman, P. S. 1982. Immunotherapy. In Progress in Allergy, Vol. 32. K. Ishizaka, editor. S. Karger, Basel, Switzerland. 318-346.

13. Van Metre, T. E., Jr., N. F. Adkinson, Jr., F. J. Amodio, L. M. Lichtenstein, M. R. Mardiney, P. S. Norman, G. L. Rosenberg, A. K. Sobotka, and M. D. Valentine. 1980. A comparative study of the effectiveness of the Rinkel method and current standard method of immunotherapy for ragweed pollen hay fever. J. Allergy Clin. Immunol. 66: 500-513.

14. Norman, P. S. Skin testing. 1980. In Manual of Clinical Immunology. 2. N. R. Rose and H. Friedman, editors. American Society for Microbiology, Washington, DC. 789-793.

15. Marone, M., A. K. Sobotka, and L. M. Lichtenstein. 1979. Effects of arachidonic acid and its metabolites on antigen-induced histamine release from human basophils in vitro. J. Immunol. 123:1669-1677.

16. Siraganian, R. 1971. An automated continuous flow system for the extraction and fluorometric analysis of histamine. Anal. Biochem. 57:283-294.

17. Rosenberg, G. L., R. R. Rosenthal, and P. S. Norman. 1983. Inhalation challenge with ragweed pollen in ragweed sensitive asthmatics. J. Allergy Clin. Immunol. 71:302-310.

18. Naclerio, R. M., H. L. Meier, A. Kagey-Sobotka, P. S. Norman and L. M. Lichtenstein. 1984. In vivo model for the evaluation of topical anti-allergic medications. Arch. Otolaryngol. 110:25-27.

19. Imanari, T., T. Kaizu, H. Yoshida, K. Yates, J. V. Pierce, and J. J. Pisano. 1976. Radiochemical assays for human urinary, salivary, and plasma kallikreins. In Chemistry and Biology of the Kallikrein-Kinin 
System in Health and Disease. J. J. Pisano and K. F. Austen, editors. DHEW Pub. No. (NIH) 76-791, Washington, DC. 205-213.

20. Schulman, E. S., H. H. Newball, L. M. Demers, F. A. Fitzpatrick, and N. F. Adkinson, Jr. 1981. Anaphylactic release of thromboxane $A_{2}$, prostaglandin $\mathrm{D}_{2}$, and prostacyclin from human lung parenchyma. Am. Rev. Respir. Dis. 124:402-406.

21. Adkinson, N. F., Jr. 1977. Prostaglandin production by human peripheral blood cells in vitro. J. Lab. Clin. Med. 90:1043-1053.

22. Snedecor, G. W., and W. G. Cochran. 1967. Statistical Methods. Sixth ed. Ames, Iowa, Iowa State University Press.

23. Lichtenstein, L. M., P. S. Norman, W. L. Winkenwerder, and A. G. Osler. 1966. In vitro studies of human ragweed allergy: changes in cellular and humoral activity associated with specific desensitization. J. Clin. Invest. 45:1126-1136.

24. Peters, S. P., D. W. MacGlashan, Jr., R. P. Schleimer, R. M. Naclerio, D. Proud, W. Kazimierczak, A. Kagey-Sobotka, N. F. Adkinson, Jr., and L. M. Lichtenstein. 1984. IgE-mediated release of inflammatory mediators from human basophils and mast cells in vitro and in vivo. In Advances in Inflammation Research, Vol. 8. G. Weissmann, editor. Raven Press, New York. 227-241.

25. Dolovich, J., F. E. Hargreave, R. Chalmers, K. J. Shier, J. Gauldie, and J. Bienenstock. 1973. Late cutaneous allergic responses in isolated IgE-dependent reactions. J. Allergy Clin. Immunol. 52:38-46.

26. Solley, G. O., G. J. Gleich, R. E. Jordan, and A. L. Schroeter. 1976. Late phase of the immediate wheal and flare skin reaction: its dependence on IgE antibodies. J. Clin. Invest. 58:408-420.
27. Nagy, L., T. H. Lee, and A. B. Kay. 1982. Neutrophil chemotactic activity in antigen-induced late asthmatic reactions. N. Engl. J. Med. 306:497-501.

28. Oertel, H. L., and M. Kaliner. 1981. The biologic activity of mast cell granules. III. Purification of inflammatory factors of anaphylaxis (IF-A) responsible for causing late phase reactions. J. Immunol. 127: 1398-1402.

29. Schulman, E. S., M. C. Liu, D. Proud, D. W. MacGlashan, Jr., L. M. Lichtenstein, and M. Plaut. 1985. Human lung macrophages induce histamine release from basophils and mast cells. Am. Rev. Respir. Dis. 131:230-235.

30. Patterson, R., J. M. McKenna, I. M. Suszko, N. H. Solliday, J. J. Pruzansky, M. Roberts, and T. J. Kehoe. 1977. Living histaminecontaining cells from the bronchial lumens of humans. J. Clin. Invest. 59:217-225.

31. Naclerio, R., A. Togias, D. Proud, N. F. Adkinson, Jr., A. KageySobotka, M. Plaut, P. S. Norman, and L. M. Lichtenstein. 1984. Inflammatory mediators in nasal secretions during early and late reactions. $J$. Allergy Clin. Immunol. 73:148. (Abstr.)

32. Gleich, G. J. 1982. The late phase of the immunoglobulin Emediated reaction: a link between anaphylaxis and common allergic disease? J. Allergy Clin. Immunol. 70:160-169.

33. Graziano, F. M., L. Gunderson, L. Larson, and P. W. Askenase. 1983. IgE antibody-mediated cutaneous basophil hypersensitivity reactions in guinea pigs. J. Immunol. 131:2675-2681. 